\title{
Grain growth behavior of an AISI 422 martensitic stainless steel after hot deformation process
}

\begin{abstract}
The metadynamic softening behavior and grain size refinement of an AISI 422 martensitic stainless steel in the temperature range of $950-1150{ }^{\circ} \mathrm{C}$ was investigated by double-hit compression tests. The deformed specimens were held at deformation temperature with delay times of 5 to 300 s after achieving a strain of 0.3 . The results indicated that at deformation temperatures lower than $1050{ }^{\circ} \mathrm{C}$, the final average grain size decreases with increasing time, attaining a minimum value at $15 \mathrm{~s}$,. However, grain coarsening was observed at deformation temperatures of 1150 and $1100{ }^{\circ} \mathrm{C}$. Based on the experimental results, a model was established for estimation of the softening fraction at different deformation parameters. The finer grain size was achieved by prior fine pre-austenite grain and lower secondary deformation temperature. The initial grain size of ASTM 5.5 decreased down toASTM7 to ASTM 8.5 at the deformation temperatures of $1020^{\circ} \mathrm{C}$ and $940{ }^{\circ} \mathrm{C}$, respectively. More uniform grain distribution was obtained with decreasing initial grain size especially at lower deformation temperatures.
\end{abstract}

Keywords: AISI 422 stainless steel; Softening fraction; Grain size; Hot deformation; Grain growth

\section{Introduction}

The AISI 422 martensitic stainless steel, as one of the high strength alloys, is widely used for rotors and bolting of gas turbine blades due to its good balance of high strength and ductility [1]. To obtain optimal properties, close control of the grain size is crucial. The austenite grain coarsening occurs easily during hot forming process of steel. The coarser austenite grain will result in a coarser martensite structure, which has an adverse effect on plasticity, strength and toughness of the steel [2-5]. The desirable reduction in grain size can be obtained through careful control of the recrystallization phenomenon which may occur dynamically or metadynamically. depending on deformation conditions. It is worth mentioning that oftenly, the metadynamic recrystallization is referred as static recrystallization. While in nature they are similar, the recrystallization kinetics between deformation passes is usually faster than conventional static recrystallization (the one taking place just by heating a cold deformed microstructure). For that reason, present authors prefer the term metadynamic recrystallization, when static recrystallization occurs between hot forming passes. In any case, the stored energy of deformation, 
in the form of a dislocation substructure, is the driving force for recrystallization [6, 7]. Since, the strain rate of hot forming processes (i.e. hot forging and hot rolling) is relatively high, in many industrial processes, the final microstructure is controlled by static or metadynamic recrystallization, rather than by dynamic recrystallization

Forming techniques such as forging and rolling processes, often consist of multiple pass deformation sequences to conversion of ingots into billets with round, square or rectangular shapes [13]. In a practical forging operation the deformed billet is unavoidably held at high temperature for a while between and after deformation passes [2]. The effect of holding time at high temperature has a great influence on the microstructural evolution of the forged alloys [14]. After hot deformation process or during inter pass times, the microstructure of deformed alloy is continuously restored [15, 16]. Therefore, it is important to investigate the metadynicamic recrystallization plus the subsequent grain growth of the deformed alloy in order to obtain the most desirable microstructure and best mechanical properties of the final products $[17,18]$.

Several investigations have been carried out on the recrystallization behavior and microstructural characterization of martensitic stainless steels [19-21]. However, there are little published data regarding the effect of the prior austenite grain size and the final deformation temperature on the final grain size of these steels. Hence, in the current work, softening and grain growth behavior of AISI 422 steel at different deformation temperatures and inter pass times was investigated. For this purpose, hot compression tests were performed over a temperature range of $950-1150{ }^{\circ} \mathrm{C}$ for different inter-pass times (5-300s) to investigate the softening behavior and grain size distribution. In addition, double-hit compression tests were performed at different temperatures in order to assess the effect of second-pass deformation on the grain size of the deformed specimens.

\section{Experimental procedure}

An AISI 422 martensitic stainless steel with the following chemical composition: $0.21 \% \mathrm{C}, 0.29 \% \mathrm{Si}$, $12.02 \% \mathrm{Cr}, 0.62 \% \mathrm{Mn}, 0.96 \% \mathrm{Ni}, 0.96 \% \mathrm{Mo}, 1.02 \% \mathrm{~W}$ (wt $\%$ ) and Fe (balance), was used in the present study. Cylindrical specimens with $5 \mathrm{~mm}$ in diameter and $10 \mathrm{~mm}$ in height were prepared using an electrical discharge machining (EDM) according to ASTM A1033 standard. Specimens were extracted from the central part of the hot forged billet to ensure the uniformity of the microstructure. Hot compression tests were carried out in a BAEHR 805D/L dilatometer (BAEHR-Thermoanalyse GmbH, ). The designed thermo-mechanical cycles are shown schematically in Fig. 1. Specimens were preheated to 
$1200^{\circ} \mathrm{C}$ for $5 \mathrm{~min}$ to achieve an homogenous austenitic structure. Then they were cooled down to deformation temperature (over a range from 950 to $1150^{\circ} \mathrm{C}$ ) and held for $20 \mathrm{~s}$ to eliminate the thermal gradient prior to deformation. Then sample were deformed to strain of 0.3 . All tests were performed at a constant strain rate of 1 per second. After the first deformation step, followed by an unloading period (5$300 \mathrm{~s}$ ), a second deformation pass was performed at the same temperature and strain rate to a small strain of 0.1 to mechanically derive the softening fraction between passes. The deformed specimens were immediately quenched just after the second compression step. Then, metallographic specimens were cut through the longitudinal direction for microstructural observation purposes. This was done by a Clemex image analyzer software.

In the second stage of this study, double-hit compression test were conducted to investigate the effect of second-pass temperature on the final grain size. The first compression step was conducted at temperatures of 1150,1100 and $1050{ }^{\circ} \mathrm{C}$ to a strain of 0.3 followed by $60 \mathrm{~s}$ unloading at the same deformation temperature. The second compression step was performed to a strain of 0.3 at lower temperatures than in the first hit, namely, 1020, 980 and $940{ }^{\circ} \mathrm{C}$. After the second deformation step the specimens were unloaded and maintained for $120 \mathrm{~s}$. The total cycle is schematically shown in Fig. 2. The specimens were polished according to ASTM E3 standard and then the prior austenite grain boundaries revealed via a chemical etching solution with the following reagent: $3 \mathrm{~g} \mathrm{CuCl}_{3}, 4 \mathrm{~g} \mathrm{FeCl}_{3}, 10$ $\mathrm{ml} \mathrm{HCl}$ and $50 \mathrm{ml} \mathrm{H}_{2} \mathrm{O}$.

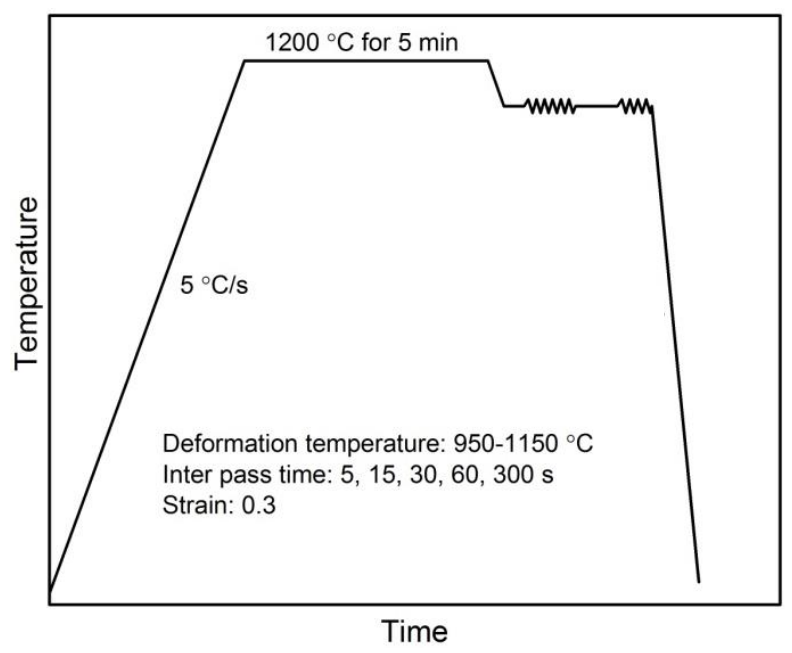

Fig. 1. Schematic illustration of compression tests. 


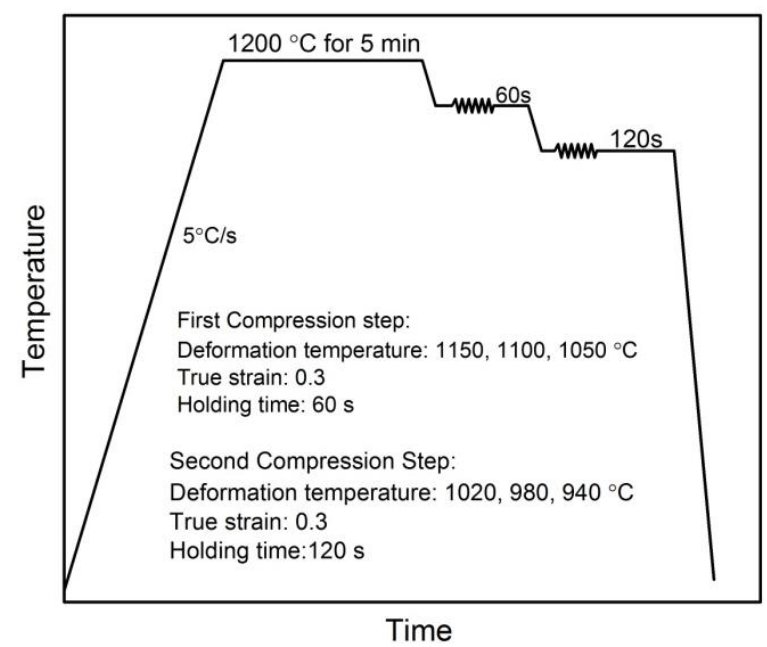

Fig. 2. Schematic of the double-hit compression test at different deformation temperatures.

\section{Results and discussion}

\subsection{Flow stress-strain curves}

It is well known that depending on deformation parameters, the recrystallization phenomenon can result in grain refining or coarsening. The final grain size of the deformed alloy is basically dependent on two factors: hot deformation conditions and holding parameters (time and temperature). Dynamically recrystallized grains can appear during the development of hot deformation process itself, which typically results in grain refinement of the microstructure. However, and as already mentioned, after the deformation process (between passes) two microstructural mechanisms can be activated. One is the metadynamic recrystallization by which new grains are nucleated and then grow consuming either the deformed or dynamically recrystallized grains. Here the driven force of the process is to eliminate the internal defects (dislocations) of the microstructure. The other, once the metadynamic recrystallization has finished, is the grain growth, where the driven force is to reduce the energy associated to grain boundaries. . Generally, at high deformation temperature, metadynamic recrystallization can occur very fast and then the final grain size is basically controlled by the grain growth step if interpass time is enough. However, depending on deformation parameters, and specially, at low temperature (strain rate, strain and temperature) the governing phenomena dictating the final grain size is the metadynamic recrystallization rather than grain growth 
The true stress-strain curves of the AISI 422 steel deformed to a true strain of 0.3 under different deformation temperatures is shown in Fig. 3. It is evident that the deformation temperature has considerable effect on the flow stress curve. It is also evident that no dynamic recrystallization is taking place as the flow curves are continuously increasing. Softening is basically controlled by dynamic recovery..

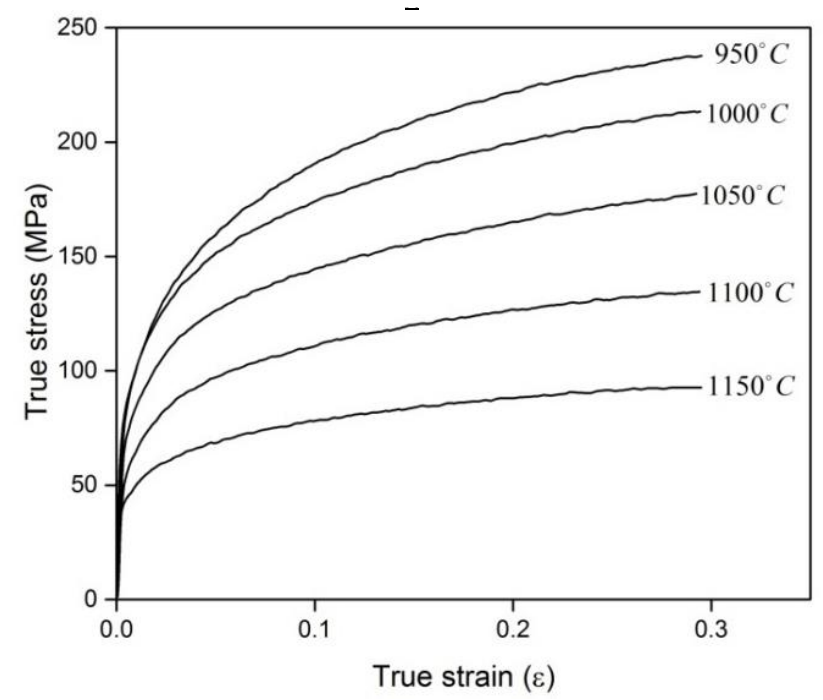

Fig. 3. Flow stress curves at true strain of 0.3 under different deformation temperatures.

The flow stress behavior in the second compression step was significantly dependent on deformation temperature and holding time. Generally, the yield stress in the second compression step increases, which may be attributed to the retained strain hardening and eventually grain refinement during the holding time [22]. An example of double-hit hot compression curves at a deformation temperature of $950{ }^{\circ} \mathrm{C}$ under different inter-pass times are illustrated in Fig. 4. In general terms softening happened during the inter pass times as illustrated by the lower stress values of the flow curve of the second hit. When the interpass time was low (i.e. 5s) the flow softening was very minor. However by increasing the inter pass time to $60 \mathrm{~s}$, more softening happened in the deformed alloy and the second curve dropped further compared to previous test. The flow stress decline is considerably small by further increase in time up to $300 \mathrm{~s}$ in comparison with the former inter pass time. After hot compression at this low deformation temperature, the grains were elongated and recrystallized grains is not seen at the preaustenite grain boundaries just after the deformation, while by increasing the holding time, the 
recrystallized grains have appeared at the austenite grain boundaries. However, at deformation temperature of $1150{ }^{\circ} \mathrm{C}$, the microstructural observations were indicated that recrystallized grains were formed from primary grain boundaries just after deformation process. Therefore, static recrystallization can be considered as the main softening mechanism at lower deformation temperatures whereas metadynamic recrytallization is more favorable at higher deformation temperatures.

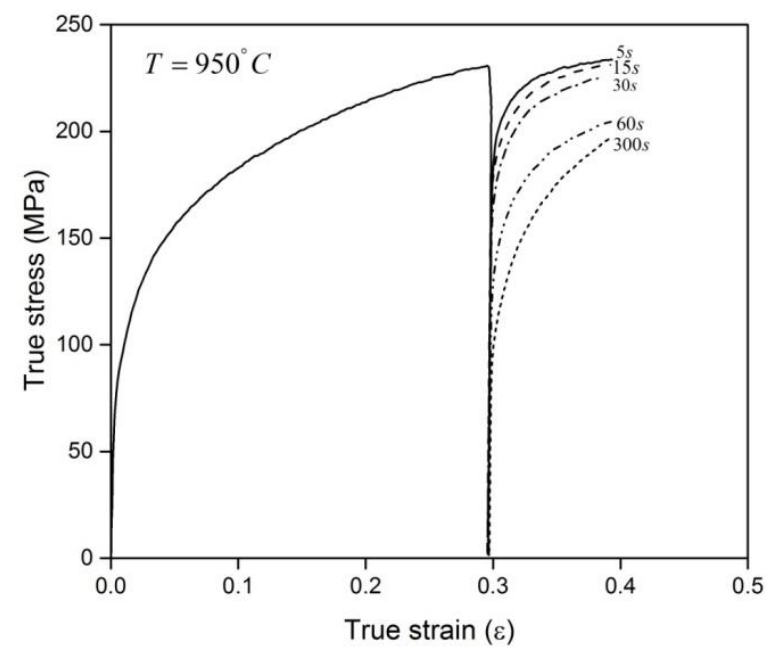

Fig. 4. Flow stress curves of the first and second compression step at deformation temperature of $950{ }^{\circ} \mathrm{C}$ under different inter pass times.

\subsection{Recrystallization softening}

The softening fraction which occurred during inter-pass time can be calculated by several methods [23]. In this work, the $0.2 \%$ offset stress method was used to estimate the softening fractions as follows:

$\mathrm{X}=\frac{\sigma_{\mathrm{m}}-\sigma_{2}}{\sigma_{\mathrm{m}}-\sigma_{1}}$

where $\sigma_{\mathrm{m}}$ is the final stress level prior to unloading, and $\sigma_{1}$ and $\sigma_{2}$ are $0.2 \%$ offset stress in the first and second deformation step, respectively. The calculated softening fractions $(\mathrm{X})$ for various deformation temperatures $\left(950-1150^{\circ} \mathrm{C}\right)$ and inter pass times $(5-300 \mathrm{~s})$ are listed in Table 1.

Table 1. Softening fractions under various deformation temperatures and inter pass times. 


\begin{tabular}{|c|c|c|c|c|c|}
\hline Inter pass time $(\mathrm{s})$ & $\mathrm{X}\left(950^{\circ} \mathrm{C}\right)$ & $\mathrm{X}\left(1000^{\circ} \mathrm{C}\right)$ & $\mathrm{X}\left(1050^{\circ} \mathrm{C}\right)$ & $\mathrm{X}\left(1100^{\circ} \mathrm{C}\right)$ & $\mathrm{X}\left(1150^{\circ} \mathrm{C}\right)$ \\
\hline 5 & 0.29 & 0.34 & 0.37 & 0.59 & 0.82 \\
\hline 15 & 0.35 & 0.54 & 0.69 & 0.82 & 0.94 \\
\hline 30 & 0.52 & 0.62 & 0.77 & 0.84 & 0.96 \\
\hline 60 & 0.66 & 0.77 & 0.87 & 0.93 & 1 \\
\hline 300 & 0.87 & 0.92 & 0.94 & 0.98 & 1 \\
\hline
\end{tabular}

Fig. 5 shows the dependence of the softening fraction on the deformation temperature and inter pass time. It is observed that the softening fraction increases at increasing deformation temperatures. For instance, at an inter pass time of $5 \mathrm{~s}$, the softening fraction is only 0.29 at a deformation temperature of $950{ }^{\circ} \mathrm{C}$, while it increases to 0.82 at $1150{ }^{\circ} \mathrm{C}$. This is obviously due to the fact that the softening and grain growth mechanisms are thermally activated .The main softening fraction at a deformation temperature of $1150{ }^{\circ} \mathrm{C}$ occurs at very short inter pass time (less than $5 \mathrm{~s}$ ), while at lower deformation temperature the major of softening occurs in longer holding times. Therefore, the softening rate of deformed alloy at high deformation temperature is significantly high, immediately after commencing deformation processes as a consequence of high dislocation density, but it drops in longer time. As mentioned in the previous section, at high deformation temperature the softening obtained as consequence of DRX-grains growth (metadynamic recrystallization), while SRX is responsible for softening at lower deformation temperature. Therefore, growth of MDRX grain initiated immediately after hot deformation process at sufficiently high temperature but at low deformation temperature, the nucleation of new recrystallized grains will be initiated after an incubation time [24].

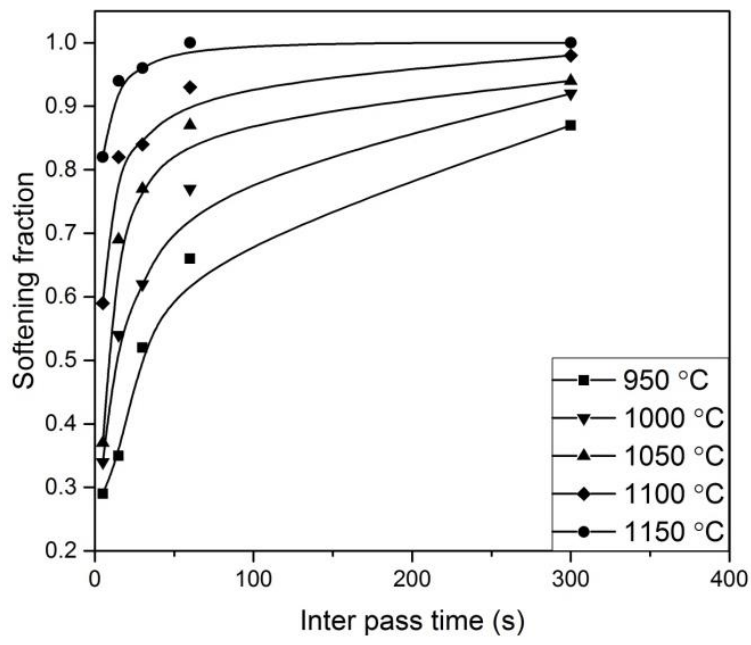


Fig. 5. Effect of deformation temperature and inter pass time on softening fraction.

\subsection{Recrystallization kinetics}

The kinetics of recrystallization after deformation is generally characterized by an Avrami type equation, which expressed in terms of the experimental time for $50 \%$ recrystallization, is given by [25, 26];

$\mathrm{X}=1-\exp \left[-0.693\left(\frac{t}{t_{0.5}}\right)^{n}\right]$

where $\mathrm{X}$ is the softening fraction, $\mathrm{t}$ is the inter pass time, $\mathrm{n}$ is the Avrami exponent and $\mathrm{t}_{0.5}$ is the time for $50 \%$ recrystallization. To determine $n$, the experimental softening results in the form of $\ln (\ln (1 / 1-X))$ were plotted versus $\ln (\mathrm{t})$ as shown in Fig. 6, and the value of $\mathrm{n}$ is obtained as the slope of the trend line, resulting here in an mean value of 0.43 . However, this value is lower than the range of $1-1.6$ generally reported for low alloy steels by Sellars and Davies [27], that indicated that this martensitic stainless steel has a lower recrystallization rate compared to low alloy steels [28]. Since the initial grain size is the same for different deformation conditions, the to.5 can be represented by a simplified expression as follows:

$t_{0.5}=A \varepsilon^{p} \exp \left(\frac{Q}{R T}\right)$

where $\mathrm{A}$ is material constant, $\varepsilon^{*}$ is the strain rate, $\mathrm{p}$ is strain rate exponent, $\mathrm{Q}$ is the apparent activation energy of recrystallization, $\mathrm{T}$ is the absolute temperature $(\mathrm{K})$ and $\mathrm{R}$ is the universal gas constant $(8.314$ $\mathrm{J} / \mathrm{mol} \mathrm{K})$ Considering that strain rate was kept constant $\left(1 \mathrm{~s}^{-1}\right.$ for all compression testing), to.5 is independent of strain rate.The values of $\mathrm{Q}$ and $\mathrm{A}$ from the plot of $\operatorname{lnt} 0.5$ versus $1 / \mathrm{T}$ as illustrated in Fig. 7 and they resulted to be as $234 \mathrm{~kJ} / \mathrm{mol}$ and $2.92 \times 10^{-9}$ (s). Therefore, the kinetics of recrystallization for the present steel can be characterized by the following equations:

$$
\begin{aligned}
& X=1-\exp \left[-0.693\left(\frac{\mathrm{t}}{\mathrm{t}_{0.5}}\right)^{0.43}\right] \\
& \mathrm{t}_{0.5}=2.92 \times 10^{-9} \exp \left(\frac{234000}{\mathrm{RT}}\right)
\end{aligned}
$$


The proposed model may be checked by comparing the experimental softening fraction $(\mathrm{X})$ and $\mathrm{t}_{0.5}$ with those predicted by Eqs. (4) and (5) as shown in Figs. 8 and 9. As can be seen the predicted results are in a good agreement with the experimental ones.

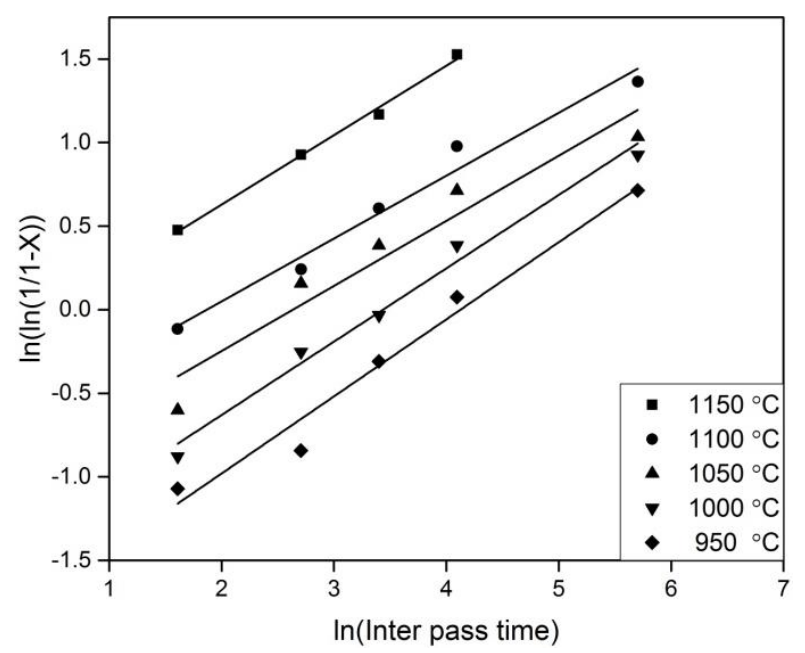

Fig. 6. Dependency of $\ln (\ln (1 / 1-X))$ on $\ln$ (inter pass time) for different deformation conditions.

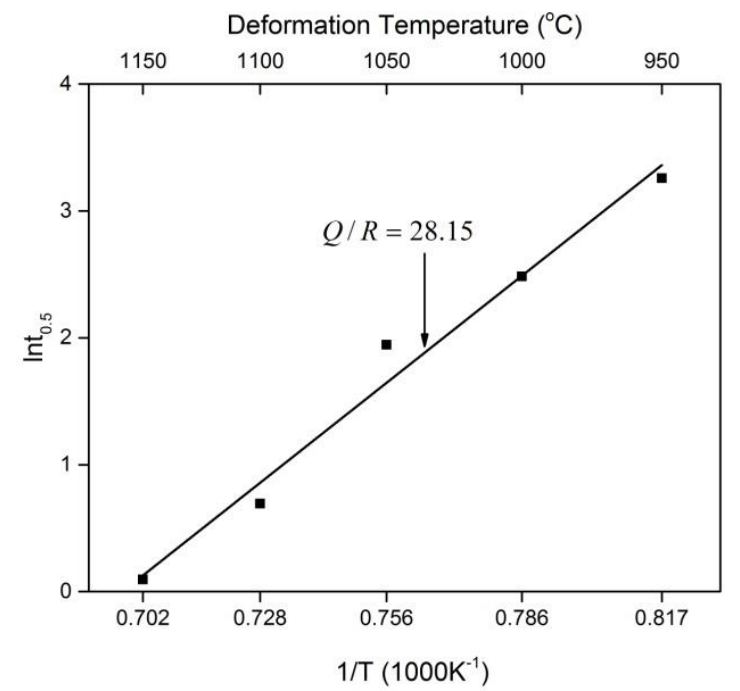

Fig. 7. Calculation of activation energy for recrystallization by plotting $\operatorname{lnt}_{0.5}$ versus $1 / \mathrm{T}$. 


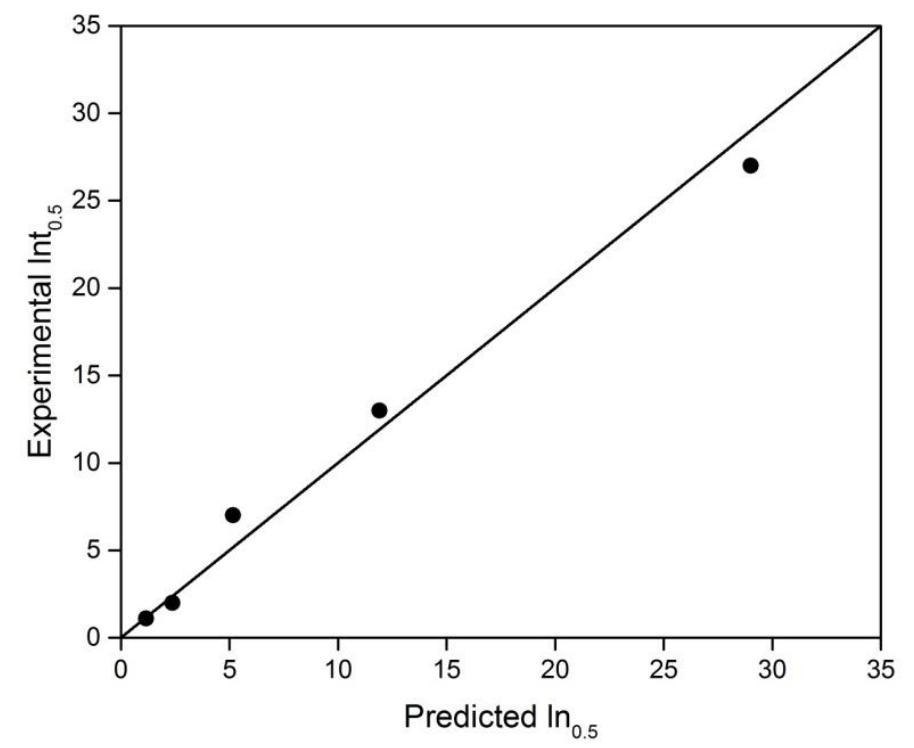

Fig. 8. Comparison between the experimental and predicted $\ln t_{0.5}$.

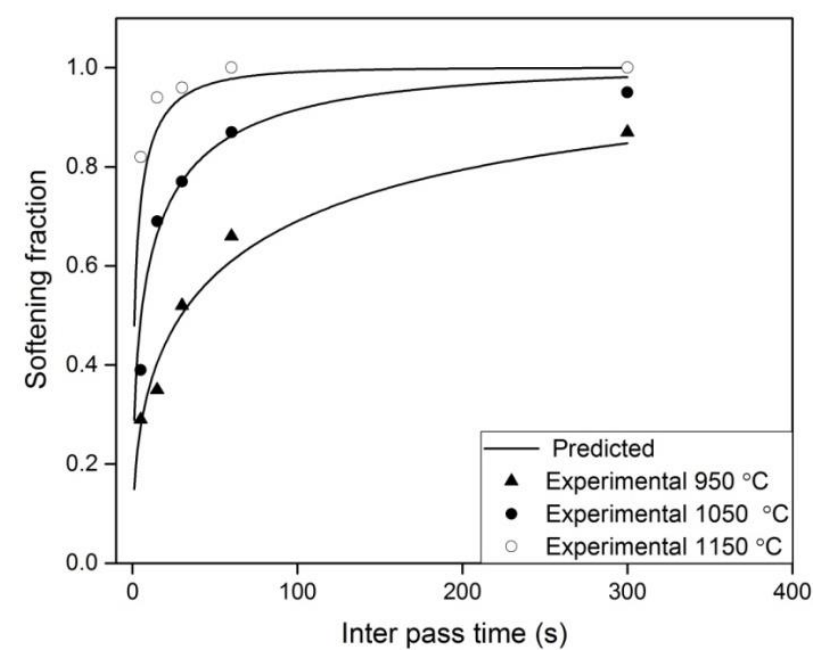

Fig. 9. Comparison between the calculated fraction softening of recrystallization determined by the proposed model and those obtained from the experiments.

\subsection{Microstructural investigations}

The microstructure of the as-received steel exhibits a coarse and equiaxed-grain structure with an average grain size about ASTM 5.3. The microstructures of the deformed specimens at $950{ }^{\circ} \mathrm{C}$ under different inter pass times are shown in Fig.10.. The microstructure of the deformed specimens at $950{ }^{\circ} \mathrm{C}$ after 5 and $15 \mathrm{~s}$ of interpass times are shown in Fig. 10 (a) and (b), respectively. It can be seen that at the initial stages of recrystallization process, despite most of unchanged microstructure (unrecrystallized microstructure), a few, small, new recrystallized grains, nucleated at prior austenite grain boundaries are recognizable. Therefore, at this stage of deformation, the recrystallized grains are greatly localized and 
non-uniformly distributed. In this regards, while the recrystallized fraction is as high as 0.52 (Fig. 10 c) some of the primitive austenite grain boundaries are still inactivated as nucleation sites.

Also, the grain size of the deformed specimens at $950{ }^{\circ} \mathrm{C}$ after different holding times is shown in Table 1. At this relatively low deformation temperature, lack of sufficient thermal energy for recrystallization caused grain elongation. However, referring to Fig. 11, it is evident that strain localizes mainly on the triple points (intersection of three grain boundaries) which provides preferential nucleation sites for recrystallization. In this regards, approximately 5\% recrystallized grains with a grain size of about ASTM 11 were formed at pre-austenite grain boundaries after $5 \mathrm{~s}$ of interpass time as shown in Fig. 10 (a). Also, when the holding time increases to 15 and $30 \mathrm{~s}$, the volume fraction of recrystallized microstructure increases to 10 and $20 \%$, respectively, and the necklaces of new grains forms along the boundaries as shown in Fig. 10 (b and c). Therefore, increasing the holding time causes the progress of metadynamic recrystallization and increases recrystallized volume fraction. On the other hand, it seems that the small grains, which formed during earlier stages of interpass times, began to grow and new grains were formed upon further inter pass time. The grain structure is almost fully recrystallized after $60 \mathrm{~s}$ of interpass time, providing an average size of about ASTM 8. Finally, as shown in Fig.10 (d), grain size increases to ASTM 7.2 after $300 \mathrm{~s}$, where it can be attributed to the additional time available for grain growth. As clearly seen in Fig. 10(d), even after a long inter pass time a relatively non-uniform grain size distribution was obtained.

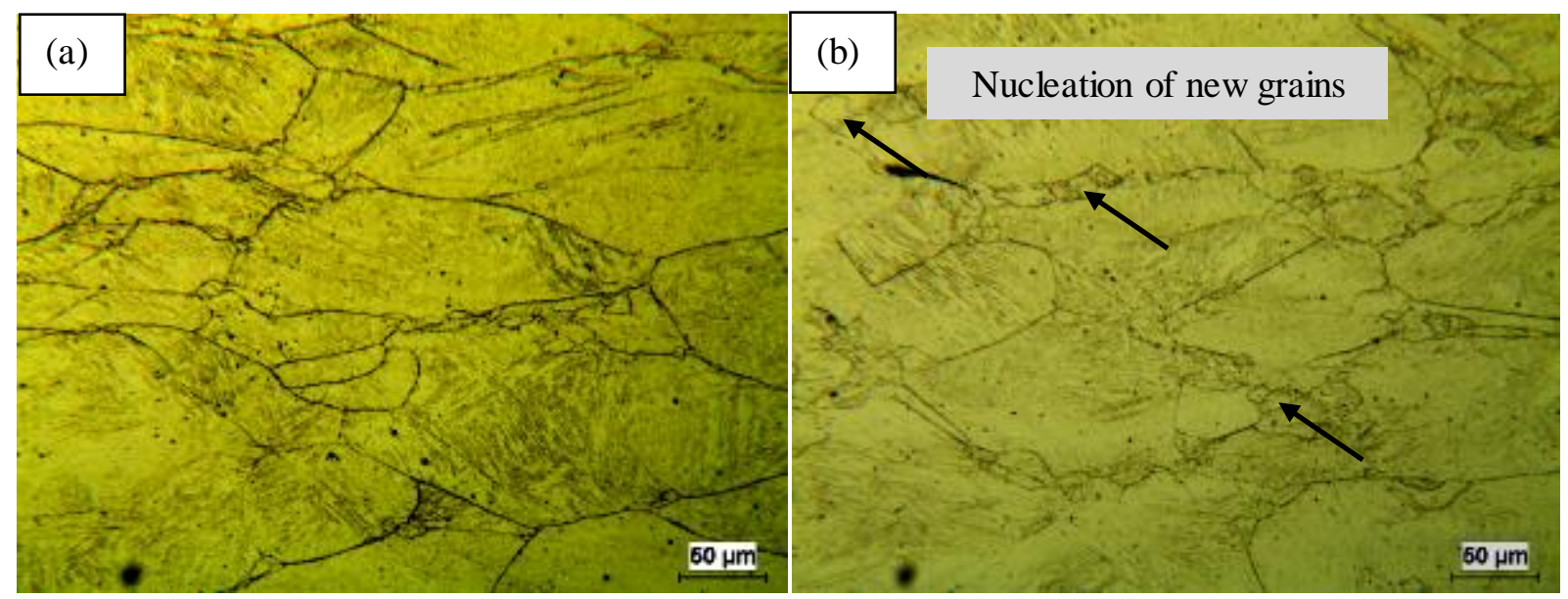



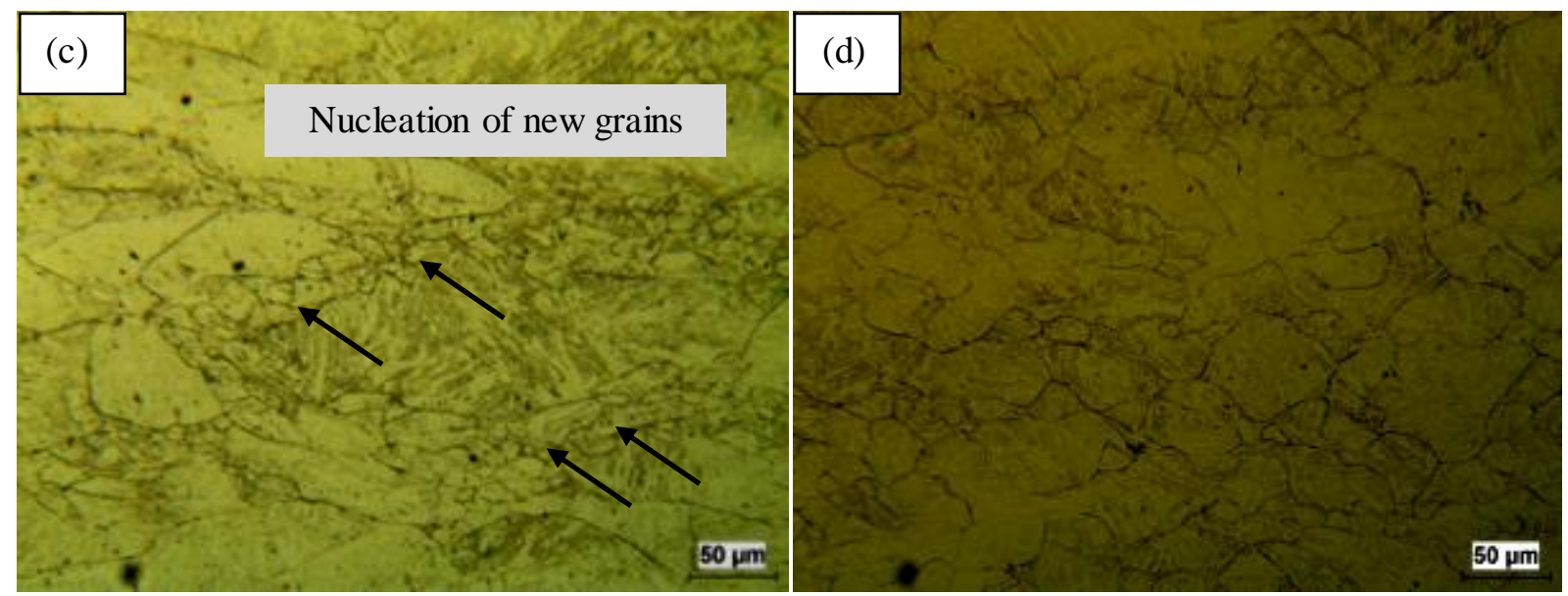

Fig. 10. Optical micrographs of the deformed specimens at $950{ }^{\circ} \mathrm{C}$ under different inter pass times; (a) $5 \mathrm{~s}$, (b) $15 \mathrm{~s}$, (c) $30 \mathrm{~s}$ and (d) $300 \mathrm{~s}$.

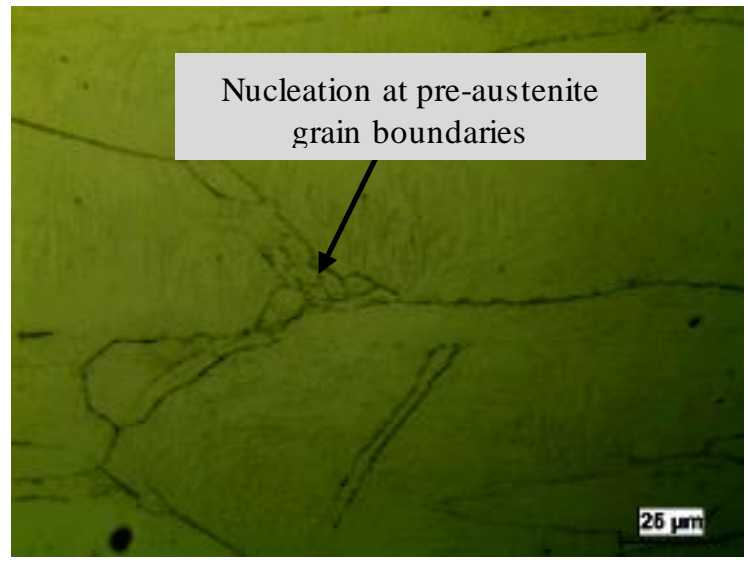

Fig. 11. Nucleation of new recrystallized grains from primary austenite grain boundaries at deformation temperature of 950 ${ }^{\circ} \mathrm{C}$ after $5 \mathrm{~s}$.

Table 1. ASTM grain size of deformed specimen at $950{ }^{\circ} \mathrm{C}$ for different inter pass time estimated by Clemex image analyzer software.

\begin{tabular}{|c|c|c|c|c|c|}
\hline Inter pass time (s) & 5 & 15 & 30 & 60 & 300 \\
\hline ASTM grain size & $5.2,5 \% 12$ & $5.2,10 \% 11$ & $5.2,20 \% 10$ & 8 & 7.2 \\
\hline
\end{tabular}

The plots of austenite-grain size against inter pass time under deformation temperatures of 1100 and $1150{ }^{\circ} \mathrm{C}$ are shown in Fig. 12 (a). It can be seen that a sharp rise of grain size is observed at the beginning of the holding time, while the grain size increases only slightly with further increasing of holding time. As it is clear from Fig. 12 (a), the grain size has been increased continuously just after 
deformation process, that can be the consequence of pre-existing recrystallized grain growth. Therefore, the metadynamic recrystallization (MDRX) may be considered as the dominant softening mechanism in these deformation temperatures and accordingly the initial unrecrystallized structure replaces dominantly by the recrystallized grains. The grain growth behavior at deformation temperature of 1050 and $1000{ }^{\circ} \mathrm{C}$ is shown in Fig. 12 (b). In these deformation conditions, the average grain size is decreased to a minimum value with increasing holding time, and then it increased continuously with further unloading time. Elongated grains were observed at the deformed specimens after $5 \mathrm{~s}$ unloading and a portion of new recrystallized grains appear at the primary austenite grain boundaries. The drop in the average grain size indicated that some new grains were formed through SRX or MDRX phenomena. By increasing unloading time to $15 \mathrm{~s}$, the average grain size decreases to ASTM 7.7 and ASTM 8.5 at deformation temperature of 1050 and $1000{ }^{\circ} \mathrm{C}$, respectively. However, the new recrystallized grains grow rapidly by further increase in time and consequently the grain coarsening occurs.

According to the obtained results, the grain growth can be considered as the main process of microstructural variation during holding time and grain size is related not only to the deformation parameters but also to the holding parameters. From the Figs. 12(a and b), it maybe concluded that the rapid grain growth occurs at deformation temperatures above $1050{ }^{\circ} \mathrm{C}$. Therefore, it is a difficult task to achieve a fine grain structure after forging process because the additional grain growth can occur at these sufficiently high deformation temperatures and enough holding time. In this regards, at the following stage of this work the grain coarsening behavior of the deformed alloy at deformation temperatures of 1020,980 and $940{ }^{\circ} \mathrm{C}$ (i.e. as the second compression step) was studied.
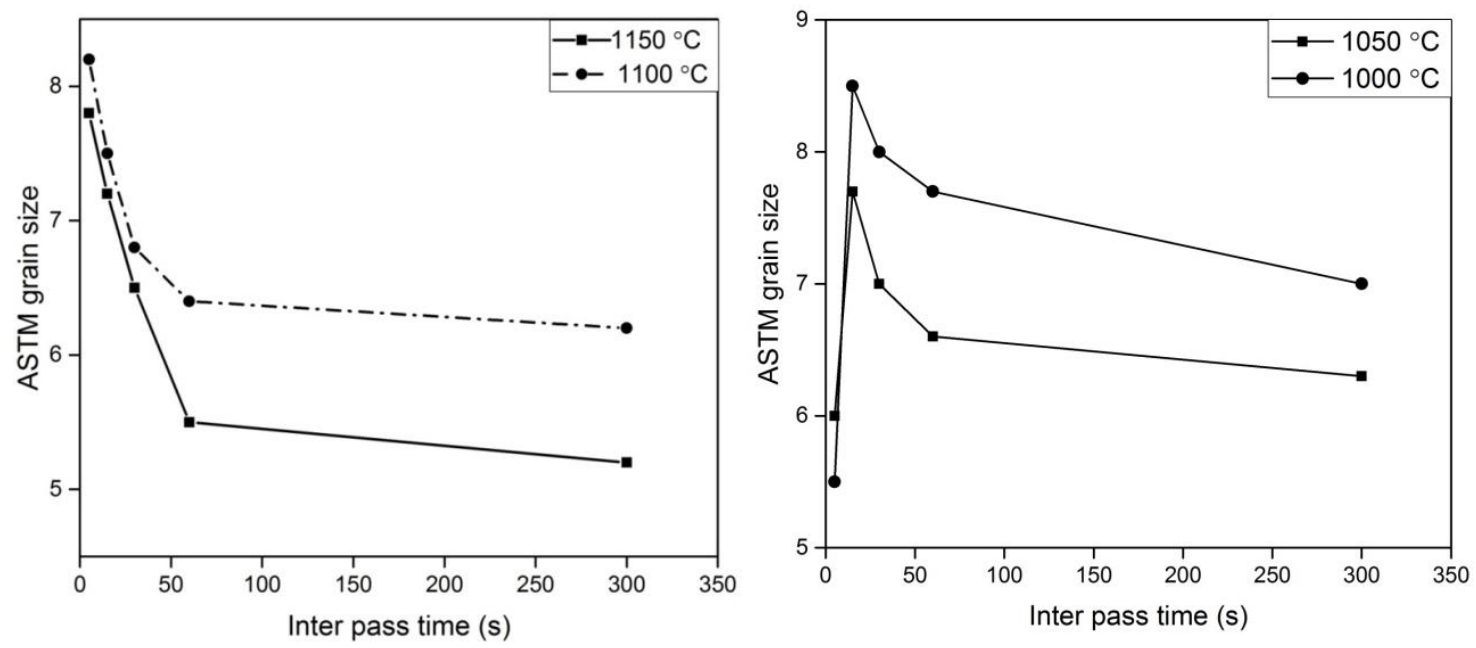

Fig. 12. Austenite grain size under different holding time at deformation temperatures of (a) 1100 and $1150{ }^{\circ} \mathrm{C}$ and (b) 1000 and $1050{ }^{\circ} \mathrm{C}$.

\subsection{The effect of deformation parameters on the grain size refining}


Generally, in the forge shops after hot deformation process, the forged products unavoidably held at high temperature for relatively long time. In order to achieve the final desired fine microstructure, it is necessary to control the austenite grain growth at such a high holding temperature. In this regards, final stage grain growth behavior was studied under a double-hit compression test as shown schematically in Fig. 2. The final grain size in the first deformation step is considered as initial grain size for second compression step. As mentioned in the previous section, the average grain size at deformation temperatures of 1150,1100 and $1050{ }^{\circ} \mathrm{C}$ after $60 \mathrm{~s}$ holding time are calculated as ASTM 5.5, 6.4 and 7.7, respectively. The second deformation step is performed at different temperatures of 1020, 980 and $940{ }^{\circ} \mathrm{C}$ followed by $120 \mathrm{~s}$ holding as the corresponding deformation temperatures. Fig. 13 shows the grain size of double-hit compression tests at different conditions. It is evidence that the finer grain size can be achieved through finer initial grain size (lower deformation temperature in the first compression step). As the grain size decreases in the first deformation step, the grain boundaries area increase, providing more sites for nucleation of new recrystallized grains in the second deformation step, consequently reduces the final grain structure. In addition, the final grain size is increased with increasing the deformation temperature of second step, where it can be attributed to higher grain-growth rate under higher deformation temperature. The optical micrographs of specimens deformed at1050 ${ }^{\circ} \mathrm{C}$ as initial deformation temperature and at 1020, 980 and $940{ }^{\circ} \mathrm{C}$ as second deformation temperatures are illustrated in Fig. 14. In order to achieve a uniform structure and with no additional grain growth, the holding time is kept as $60 \mathrm{~s}$ and $120 \mathrm{~s}$ in the first and second step, respectively. As a result, the finer grain structure is achieved at lower deformation temperature in both compression steps. In addition, more non-uniform distribution of recrystallized grains was obtained in the initial coarse-grain structure. Fig. 15 shows the recrystallized grain size distributions. Note the average grain size indication in the histogram. It is observed that the grain size distribution is relatively uniform in all temperatures. In addition, mean grain size increases as the deformation temperature increase, extending the grain-size distribution to larger sizes. The final microstructure developed at a constant deformation temperature in second step for specimen with small grain size, consist of more uniform grain distribution. Therefore, the final compression step should be conducted at $940{ }^{\circ} \mathrm{C}$ to hinder the considerable grain growth in a relatively long time after deformation. Although, deformation process can be performed in the single phase area, however it can not be conducted at lower temperatures. As shown in Fig. 12, the grain growth rate is relatively negligible at longer inter pass time. In this regards, the average grain size is 
about 9.3 after 300s unloading at $940{ }^{\circ} \mathrm{C}$, which indicates the very slow grain growth at this low deformation temperature.

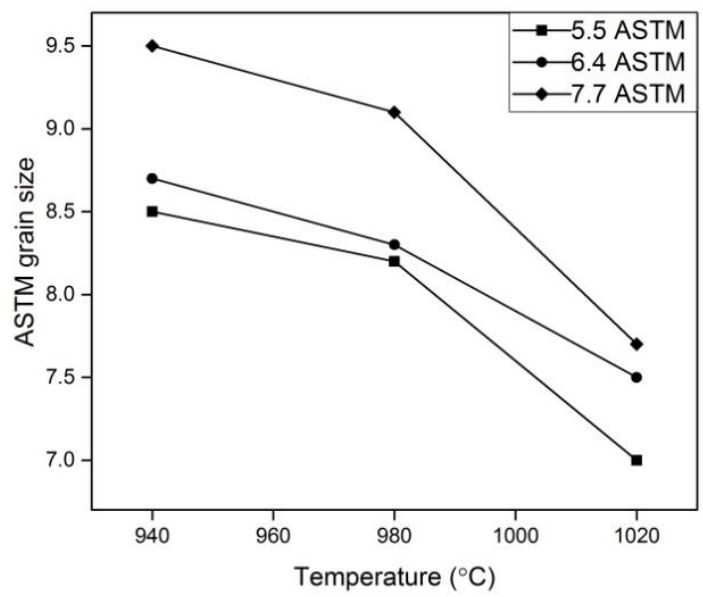

Fig. 13. Effect of initial grain size on the grain refining of double-hit compression test under different deformation temperatures.

Fig. 14. Optical micrographs in double-hit compression; with initial deformation temperature of $1050{ }^{\circ} \mathrm{C}$ and the second temperature of: (a) $1020^{\circ} \mathrm{C}$, (b) $980{ }^{\circ} \mathrm{C}$, (c) and (d) $940{ }^{\circ} \mathrm{C}$ at different magnifications .
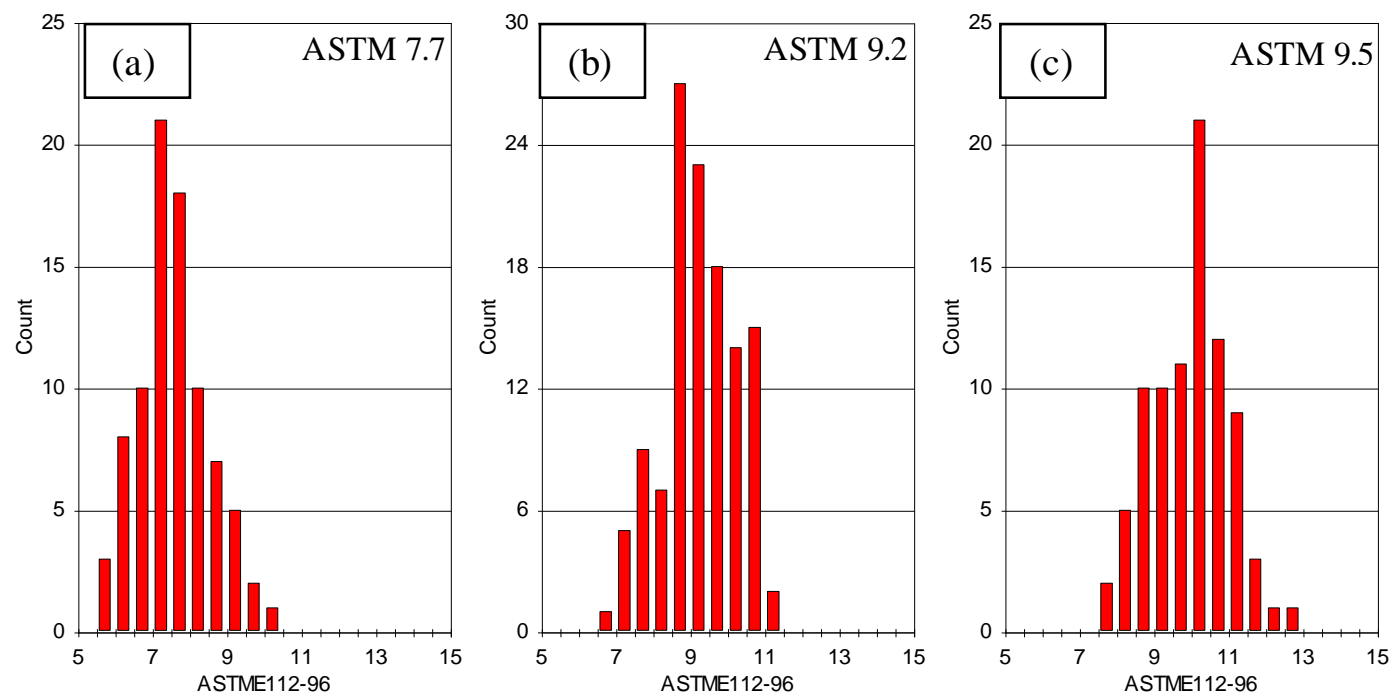

Fig. 15. Grain size distribution of recrystallized grains at $1050{ }^{\circ} \mathrm{C}$ in first deformation step under different deformation temperature of (a) 1020 , (b) 980 , (c) $940^{\circ} \mathrm{C}$ as second deformation step.

\section{Conclusions}

The effect of hot deformation parameters on the softening behavior and grain refining of AISI 422 martensitic stainless steel under double-hit compression test were investigated. In addition the effect of primary austenite grain size and final deformation temperature were studied on the final grain size. The following conclusions can be drawn:

1. Grain growth is one of the main softening process contributing to microstructural variation during holding time, which it can be increases with increasing holding time and deformation temperature.

2. At high deformation temperatures, the softening fraction rate is very high at the begging of holding time but it decreases over longer time. Also, at such a high deformation temperature a sharp rise of grain size is observed at short holding period, while the grain size increases only slightly over a longer time.

3. At deformation temperature of $950{ }^{\circ} \mathrm{C}$, the static recrystallization is the main softening mechanism and the structure is fully recrystallized after $60 \mathrm{~s}$ unloading time resulting an average grain size of 
ASTM 8 while the grain size of the deformed alloy reaches to ASTM 7.2 by additional inter pass time to $300 \mathrm{~s}$.

4. The rapid grain growth occurs at deformation temperatures above $1050{ }^{\circ} \mathrm{C}$. Therefore, the final compression step should be conducted at lower than this temperature to hinder the considerable grain growth in a relatively long time after deformation.

5. In double hit-compression test; more uniform grain distribution is achieved if the initial grain size is small where can be attributed to nucleation of recrystallized grains on the finer pre-austenite grain boundaries.

References:

[1] N. V. Dashunin, E. P. Manilova, and A. I. Rybnikov, Phase and structural transformations in $12 \%$ chromium steel EP428 due to long term operation of moving blades, J. Met. Sci. Heat Treat. 49 (2007) 23-29.

[2] J.M. Zhanga, Z.Y. Gao, J.Y. Zhuang, Z.Y. Zhong, Grain growth model of IN718 during holding period after hot deformation, J. Mater. Proce. Tech. 101 (2000) 25-30.

[3] H. Mirzadeh, A. Najafizadeh, Hot Deformation and Dynamic Recrystallization of 17-4 PH Stainless Steel, ISIJ Int. 53 (2013) 680-689.

[4] J. Huang, Zh. Xu, Evolution mechanism of grain refinement based on dynamic recrystallization in multiaxially forged austenite, Mater. Lett. 60 (2006) 1854-1858.

[5] X. Chen, Y.C. Lin, M. Chen, H. Li, D. Wen, J. Zhang, M. He, Microstructural evolution of a nickel-based superalloy during hot deformation, J. Mater. Des. 77 (2015) 41-49.

[6] M. C. Mataya, Effect of multiple reductions on grain refinement during hot working of alloy 718, Sup. Met. App. TMS (1989) 155178.

[7] J. P. Domblesky, L. A. Jackman, R. Shivpuri, B. B. Hendrick, Prediction of grain size during multiple pass radial forging of alloy 718, (1994) 263-272.

[8] Zhouyu Zeng, Liqing Chen, Fuxian Zhu and Xianghua Liu, Static recrystallization behavior of a martensitic heat-resistant stainless steel 403Nb, Acta Metall. Sin.(Engl. Lett.)Vol.24 No.5 pp381-389 October 2011.

[9] Zhouyu Zeng, Liqing Chen, Fuxian Zhu and Xianghua Liu, Dynamic Recrystallization Behavior of a Heat-resistant MartensiticStainless Steel 403Nb during Hot Deformation, J. Mater. Sci. Technol., 2011, 27(10), 913-919.

[10] G. R. Ebrahimi, H. Keshmiri, M. Mazinani, A. Maldar, M. Haghshenas, Multi-stage thermomechanicalbehaviorofAISI410martensiticsteel,Mater. Sci. Eng. A 559 (2013) 520-527. 
[11] Y. Cao, H. Di, R.D.K Mirsra, X. Yi, J.Zhang, T. Ma, On the hot deformation behavior of AISI420 stainless steel based on constitutive analy sis and CSLmodel, Mater. Sci. Eng. A 593 (2014) 111-119.

[12]J. Liu a, Y.G.Liu a, H.Lin b, M.Q.Li The metadynamic recrystallization in the two-stage isothermal compression of 300 Msteel, Mater. Sci. Eng. A 565 (2013) 126-131.

[13] V. Soleymani, B. Eghbali, Grain Refinement in a Low Carbon Steel Through Multidirectional Forging J. Iro. Ste. Rea. Int. 19 (2012) 74-78.

[14] R. Abad, A.I. Fernandez, B. Lopez, J.M. Rodriguez, Effect of Initial Austenite Microstructure on the Softening Precipitation Interaction in a Low Nb Microalloyed Steel, ISIJ Int. 41 (7) (2001) 1373-1382.

[15] M. Zouari, N. Bozzolo, R. E. Loge, Mean field modeling of dynamic and post-dynamic recrystallization during hot deformation of Inconel718 in the absence of $\delta$ phase particles, Mater. Sci. Eng. A 655 (2016) 408-424.

[16] A. Bapari, A. Najafizadeh, M. Moazeny, A. Shafy ei, Simulation of radial forging conditions by third hits hot compression tests, Mater. Sci. Eng. A 491 (2008) 258-265.

[17] T. Sakai, A. Belyakov, R. Kaibyshev, H. Miura, J. J. Jonas, Dynamic and post-dynamic recry stallization under hot, cold and severe plastic deformation conditions Pro. Mate. Sci. 60 (2014) 130-207.

[18] Y. Fanga, X. Chenb, B Madiganc, H. Caoa, S. Konovalov, Effects of strain rate on the hot deformation behavior and dynamic recry stallization in China low activation martensitic steel, Fusion Eng. Desi. 103 (2016) 21-30

[19] A. A. Tchizhik, T. A. Tchizhik, A. A. Tchizhik, Optimization of the heat treatment for steam and gas turbine parts manufactured from 9-12\% Cr steels, J. Mater. Pro. Tech. 77 (1998) 226-232

[20] L. L. Wang, R. B. Li, Y. G. Liao, M. Jin, Study oncharacterizationofhotdeformationof403steel, Mater. Sci. Eng. A 567 (2013) $84-88$

[21] F. Ren, J. Chen, F. Chen, Constitutive modeling of hot deformation behavior ofX20Cr13 martensitic stainless steel with strain effect, Trans. Nonferrous Met. Soc. China 24(2014) 1407-1413.

[22] A. Belyakov, H. Miura, T. Sakai, Dy namic recry stallization in ultra fine-grained 304 stainless steel, Scr. Mater. 43 (2000) $21-26$.

[23] A.L. Fernandez, B. Lopez, J.M. Rodriguez-Ibabe, Relationship between the austenite recrystallized fraction and the softening measured from the interrupted torsion test technique, Scr. Mater. 40 (1999) 543-549.

[24] A. I. Fernández, B. López, J. M. Rodriguez-Ibabe, Static recry stallization mechanisms in a coarse-grained Nb-microalloyed austenite, Metallurgical and Materials Transactions A, 33 (2002) 3089-98.

[25] P.D. Hodgson, R.E. Gloss, and G.L. Dunlop: in 32nd Mechanical Working and Steel Processing, M.E. Kassner, ed., ISS-AIME, Warrendale, PA, (1990) 527-38.

[26] P.D. Hodgson, D.C. Collinson, and B.A. Parker: in Advances in Hot Deformation Textures and Microstructures, J.J. Jonas, T.R. Bieler, and K.J. Bowman, eds., TMS, Warrendale, PA, (1994) 41-61.

[27] Sellars, C.M., Davies, Hot working and forming processes: proceedings of an International Conference on Hot Working and Forming Processes. (1980) 3-15.

[28] M. Y. Cheng, H. Du, Y. Wei, L. Hou, B. Liu, Metadynamic recrystallization behavior and workability characteristics of HR3C austenitic heat-resistant stainless steel with processing, J. Mater. Proc. Tech. 235 (2016) 134-142. 